\title{
ChemComm
}

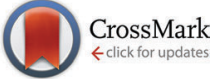

Cite this: Chem. Commun., 2016, 52,4033

Received 10th November 2015, Accepted 12th February 2016

DOI: $10.1039 / \mathrm{c} 5 \mathrm{cc} 09324 d$

www.rsc.org/chemcomm

\section{Ionic liquid electrolytes for reversible magnesium electrochemistry $\dagger$}

\author{
Mega Kar, ${ }^{a}$ Zheng Ma, ${ }^{a}$ Luis Miguel Azofra, ${ }^{a}$ Kun Chen, ${ }^{a}$ Maria Forsyth ${ }^{b}$ and \\ Douglas R. MacFarlane ${ }^{a}$
}

Mg has great potential as the basis for a safe, low cost energy storage technology, however, cycling of magnesium is difficult to achieve in most electrolytes. We demonstrate cycling of $\mathrm{Mg}$ from a novel alkoxyammonium ionic liquid. DFT calculations highlight the role that $\mathrm{Mg}$ coordination with $\left[\mathrm{BH}_{4}\right]^{-}$ions plays in the mechanism.

Magnesium metal is a cost effective, readily available metal, especially in comparison to lithium, and is reduced at relatively negative potentials, $-2.37 \mathrm{~V}$ ( $v s$. SHE), which makes it highly attractive as an anodic material for rechargeable batteries in energy storage applications. Nevertheless, there are number of challenges that need to be overcome in order to produce a reversible magnesium device. One main issue is the formation of passivating layers at the anode-electrolyte interface, in the presence of air, water, and some organic electrolytes, which inhibits the electrochemical re-oxidation of magnesium.

Some of the electrolytes used to reduce the formation of such passivating layers and thus produce reversible cycling of magnesium have been based on ethereal solvents such as tetrahydrofuran (THF). ${ }^{1}$ The presence of Lewis basic moieties such as an ether oxygen appears to be important for sufficient solvation of $\mathrm{Mg}^{2+}$ ions. ${ }^{2}$ However, the safety of such organic electrolytes at high concentrations is often questioned due to their flammable and volatile nature. To eliminate such safety concerns in electrolyte applications generally, much attention has focused on room temperature ionic liquids (RTILs) - molten salts consisting of organic cations and inorganic anions. ${ }^{3}$ They have melting points below $100{ }^{\circ} \mathrm{C}$ and in many cases are nonvolatile, non-flammable, thermally stable at high temperatures $\left(T_{\mathrm{d}}>300{ }^{\circ} \mathrm{C}\right)$, and have a wide electrochemical window which

\footnotetext{
${ }^{a}$ ARC Centre of Excellence for Electromaterials Science, School of Chemistry, Faculty of Science, Monash University, Clayton, VIC 3800, Australia. E-mail:Mega.Kar@monash.edu

${ }^{b}$ ARC Centre of Excellence for Electromaterials Science, IFM-Institute for Frontier Materials, Deakin University, 221 Burwood Hwy, Burwood, VIC 3125, Australia $\dagger$ Electronic supplementary information (ESI) available: RTILs synthesis, electrochemistry, X-ray diffraction (SEM and EDX), and supplementary computational details. See DOI: 10.1039/c5cc09324d
}

makes them suitable for the electrodeposition of highly electronegative metals such as magnesium. ${ }^{4}$

Nonetheless, the goal of producing reversible magnesium electrochemistry in the presence of RTIL based electrolytes has remained immensely challenging. It appears that several factors such as the role of the magnesium salt and the choice of the cation and anion counterparts in the RTIL are of great significance in determining the outcome of the electrodeposition and stripping processes of magnesium ions. At present, when RTILs are the main solvent, magnesium deposition is only possible when the IL is either mixed with an additive ${ }^{5}$ or co-solvents ${ }^{6}$ such as ethereal solvents, and/or organomagnesium halides such as those used in Grignard reagents. ${ }^{7}$ Recently there has also been some controversy about the reproducibility and the exact nature of the reduced magnesium product from some RTILs. ${ }^{6,8}$ Shimamura et al. recently demonstrated magnesium/lithium alloy reduction and re-oxidation when a mixture of $\mathrm{Mg}\left[\mathrm{NTf}_{2}\right]_{2}(10 \mathrm{~mol} \%)$ and $\mathrm{Li}\left[\mathrm{NTf}_{2}\right](10 \mathrm{~mol} \%)$ was added to a quaternary ammonium cation based RTIL. However, no magnesium stripping was observed in the absence of Li[ $\left.\mathrm{NTf}_{2}\right]$ and it appears that the electrochemical process in this case was heavily dominated by Li metal deposition in the form of a Li/Mg alloy. ${ }^{5}$

Whilst the challenge of using flammable ethereal solvents still remained, Mohtadi et al. demonstrated in their work reversible magnesium electrochemistry from alternative magnesium salts, such as magnesium borohydride $\mathrm{Mg}\left[\mathrm{BH}_{4}\right]_{2}$, which are strong reducing agents. ${ }^{9}$ This work clearly demonstrates enhanced electrochemical reversibility of magnesium from ethereal solvents such as dimethoxyethane (DME), which can chelate to $\mathrm{Mg}^{2+}$ ions. This inspired us to design a safer, non-volatile electrolyte based on $\mathrm{Mg}\left[\mathrm{BH}_{4}\right]_{2}$ interacting with an ether functionalized RTIL. ${ }^{10}$ Thus we report here reversible magnesium deposition/stripping from a pure RTIL electrolyte for the first time, employing a novel alkoxyammonium based RTIL, specifically $\left[\mathrm{N}_{2}(20201)(20201)(20201)\right]\left[\mathrm{NTf}_{2}\right]$ (hereafter simply referred as IL1, see Fig. 1a). $\neq$

Cyclic voltammetry (CV) plots gathered in Fig. 1b highlight the importance of both the magnesium salt and RTIL in producing reversible $\mathrm{Mg}$ cycling. For instance, in the presence of $0.1 \mathrm{M} \mathrm{Mg}\left[\mathrm{BH}_{4}\right]_{2}$ in $\mathbf{I L 1}$, both magnesium deposition and stripping 
a)

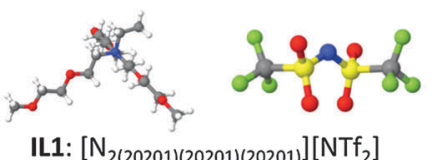

IL1: [N $\left.\mathrm{N}_{2(20201)(20201)(20201)}\right]\left[\mathrm{NTf}_{2}\right]$

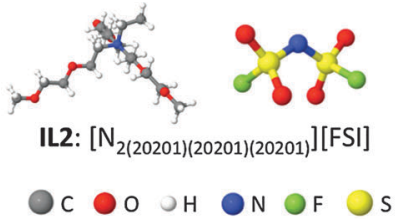

b)

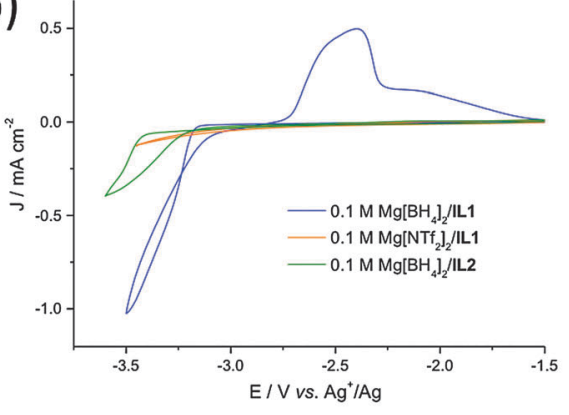

c)

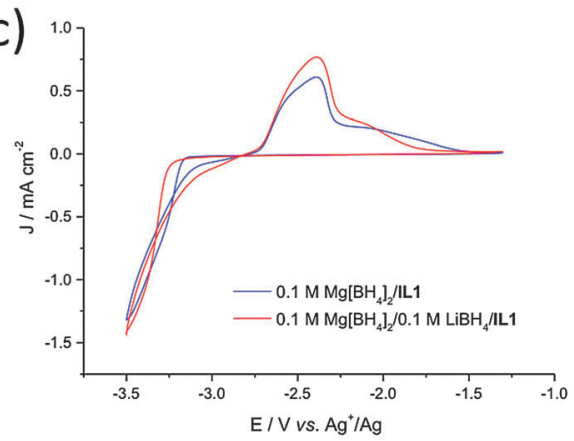

Fig. 1 (a) Cation and anion counterparts constituting IL1 and IL2 RTILs; (b) CVs vs. Ag $/ \mathrm{Ag}^{+}$for $\left.0.1 \mathrm{M} \mathrm{Mg} \mathrm{BBH}_{4}\right]_{2} / \mathrm{IL1}$ (blue), $\left.0.1 \mathrm{M} \mathrm{Mg[NTf}\right]_{2} / \mathrm{IL1}$ (yellow), and $0.1 \mathrm{M} \mathrm{Mg}\left[\mathrm{BH}_{4}\right]_{2} / \mathrm{IL2}$ (green); and (c) addition of $0.1 \mathrm{M} \mathrm{LiBH}_{4}$ (red) to $0.1 \mathrm{M} \mathrm{Mg}\left[\mathrm{BH}_{4}\right]_{2} / \mathrm{IL1}$.

were observed at $-2.80 \mathrm{~V} v$ s. $\mathrm{Ag}^{+} / \mathrm{Ag}$ (blue curve). Furthermore, Fig. S1c (ESI $\dagger$ ) demonstrates stable magnesium cycling in IL1 over 20 cycles, producing a coulombic efficiency of $60 \%$.

However no magnesium deposition/stripping is observed when the magnesium salt is changed from $\mathrm{Mg}\left[\mathrm{BH}_{4}\right]_{2}$ to $\mathrm{Mg}\left[\mathrm{NTf}_{2}\right]_{2}$ (orange curve) or when the anion in IL1 is changed from $\left[\mathrm{NTf}_{2}\right]^{-}$to $[\mathrm{FSI}]^{-}$, i.e. IL2 (green curve). A small oxidation peak becomes observable when the concentration of $\mathrm{Mg}\left[\mathrm{BH}_{4}\right]_{2}$ is increased from $0.1 \mathrm{M}$ to $0.2 \mathrm{M}$ in IL2 (Fig. S2, ESI $\dagger$ ); this peak disappears after a few cycles. This suggests that a passivating layer is formed upon deposition in this case, as discussed later in this article.

To prove the effect of $\left[\mathrm{BH}_{4}\right]^{-}$concentration in IL1, additional $\left[\mathrm{BH}_{4}\right]^{-}$was added via addition of $\mathrm{LiBH}_{4}$; Fig. 1c displays an increase in the oxidative current when $0.1 \mathrm{M} \mathrm{LiBH}_{4}$ was added to the $0.1 \mathrm{M} \mathrm{Mg}\left[\mathrm{BH}_{4}\right]_{2} / \mathbf{I L 1}$ mixture (red curve). The reductive sweep involves a greater amount of charge and the oxidative sweep peaks at a higher current in the presence of the additional $\left[\mathrm{BH}_{4}\right]^{-}$. Both reductive and oxidative processes indicate a greater amount of $\mathrm{Mg}$ being cycled, which suggests that the process is further enhanced by the co-ordination of the $\mathrm{Mg}$ by additional $\left[\mathrm{BH}_{4}\right]^{-}$anions. A similar trend was also observed by Mohtadi et al..$^{9}$ It is important to note that the deposition and stripping in these experiments is still observed around the $\mathrm{Mg}$ potential, i.e. that there is no obvious involvement of the $\mathrm{Li}$ from $\mathrm{LiBH}_{4}$ in shifting the potential more negative.

To prove that the reduction process is solely due to $\mathrm{Mg}^{2+} / \mathrm{Mg}$, the deposition of magnesium was conducted in $0.2 \mathrm{M} \mathrm{Mg}\left[\mathrm{BH}_{4}\right]_{2} / \mathbf{I L 1}$ for 12 hours. X-ray diffraction (XRD) patterns of the electrode after deposition shows (Fig. 2a) the expected diffraction peaks of magnesium at $2 \theta=31.97,34.19$, and $36.38^{\circ}$ which are assigned to the (100), (002), (101) planes of magnesium (JCPDS 04-0770). ${ }^{11}$ Furthermore, EDX measurements of the deposits obtained from this electrolyte with and without the addition of $\mathrm{LiBH}_{4}$ demonstrate that the only metal produced is $\mathrm{Mg}$ (Fig. S2a and b, ESI $\dagger$ ). These results are concordant with those of Mohtadi et al. who also observed that $\mathrm{Mg}$ was the only redox-active species involved in electrochemical cycling in their DME based electrolyte. ${ }^{9}$

To prove the nature and role of the co-ordination environment of $\mathrm{Mg}$ in these IL electrolytes, ${ }^{12}$ Fourier Transform Infrared (FT-IR) (Fig. 2b) and Raman vibrational (Fig. S3, ESI $\dagger$ ) measurements were performed when $0.25 \mathrm{M} \mathrm{Mg}\left[\mathrm{BH}_{4}\right]_{2}$ is added to IL1. DFT calculations a)
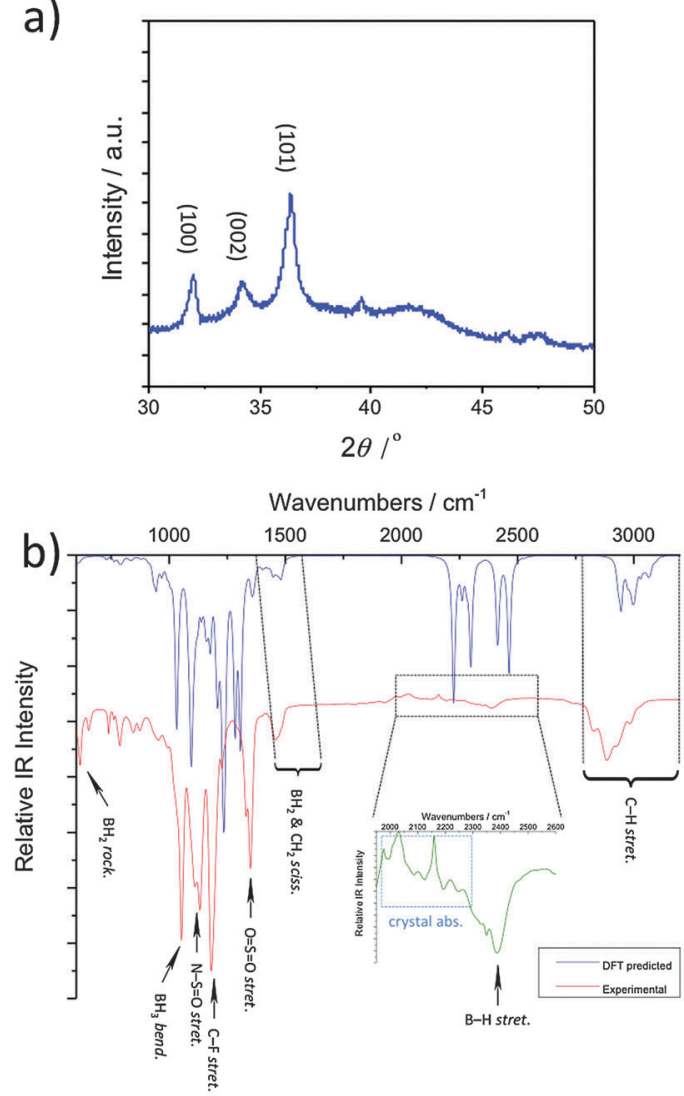

Fig. 2 (a) XRD and (b) FT-IR experimental (red) and theoretical (blue) spectra (spectral range $=3500-250 \mathrm{~cm}^{-1}$ ) of $0.25 \mathrm{M} \mathrm{Mg}\left[\mathrm{BH}_{4}\right]_{2}$ in IL1.

of the environment were also carried out (as described in ESI $\dagger$ ). Comparison of the calculated and measured vibrational spectra (Fig. 2b), in particular with respect to the $\left[\mathrm{BH}_{4}\right]^{-}$anion, confirms that the theoretical calculations are producing meaningful structures. Both the experimental FT-IR and theoretical results reveal two main $\left[\mathrm{BH}_{4}\right]^{-}$peaks at 1456 and $617 \mathrm{~cm}^{-1}$ which can be assigned to $\mathrm{BH}_{2}$ scissoring and rocking modes. The presence of $\left[\mathrm{BH}_{4}\right]^{-}$ions in the IL is also evident from a low intensity B-H stretching peak at approximately $2387 \mathrm{~cm}^{-1}$ which is not evident in the neat IL1. No significant shifts were observed in the IL bands in the experimental spectra, upon the addition of 


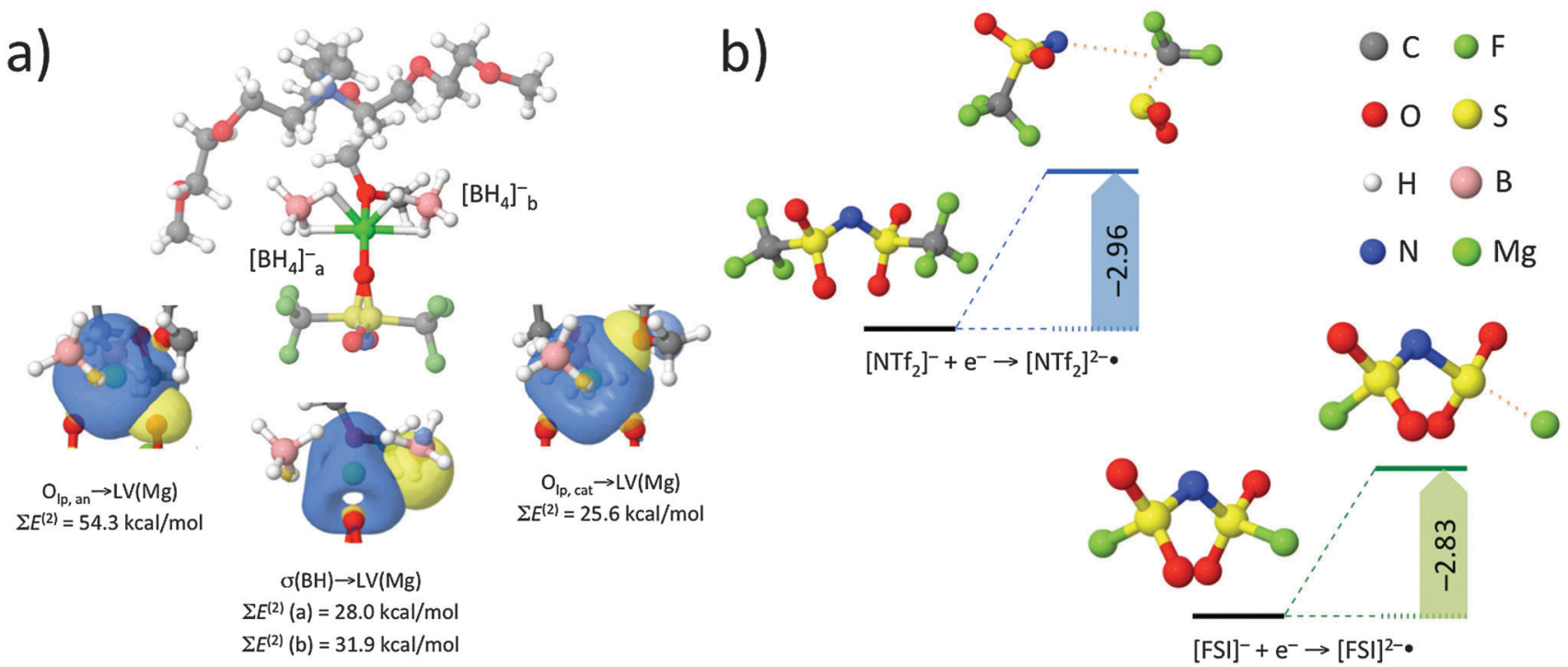

Fig. 3 (a) $\mathrm{Mg}\left[\mathrm{BH}_{4}\right]_{2} / \mathrm{IL1}$ complex and main NBO contributions around the $\mathrm{Mg}^{2+}$ ion; and (b) theoretically predicted reduction potentials (in $\mathrm{V}$ vs. Ag ${ }^{+} / \mathrm{Ag}$ ) and the reductive degradation mechanisms of the $\left[\mathrm{NTf}_{2}\right]^{-}$and $[\mathrm{FSI}]^{-}$anions.

$\mathrm{Mg}\left[\mathrm{BH}_{4}\right]_{2}$ in IL1, since the molar concentration of magnesium in the electrolyte is low compared to the IL ion concentration. On the basis of this satisfactory concordance of the calculated spectra for the $\mathrm{Mg}^{2+}$ ion in the IL, we now proceed to use the DFT calculation to further analyse the energetics of the structures and the reduction process.

The DFT calculations of the system consisting of $\mathrm{Mg}\left[\mathrm{BH}_{4}\right]_{2}^{+}$ an IL1 ion pair reveal (Fig. 3a) that the magnesium ion indeed forms a strongly bound hepta-coordinated complex that involves both anions and the cation ether oxygens, i.e. through a two-fold connection with the $\mathrm{O}$ atoms of $\left[\mathrm{NTf}_{2}\right]^{-}$, a double two-fold connection within the $\mathrm{H}\left(\delta^{-}\right)$atoms of each $\left[\mathrm{BH}_{4}\right]^{-}$anion, and a single weak bond via the $\mathrm{O}$ atom of the IL1 cation. NBO analysis, as shown in Fig. 3a and Fig. S4 (ESI†), indicates that the strength of these interactions produces stabilization energies that follow the expected order of orbital charge transfers: $\mathrm{O}_{\mathrm{lp}, \text { an }} \rightarrow$ $\mathrm{LV}(\mathrm{Mg}), \sigma(\mathrm{BH}) \rightarrow \mathrm{LV}(\mathrm{Mg})$, and $\mathrm{O}_{\mathrm{lp}, \text { cat }} \rightarrow \mathrm{LV}(\mathrm{Mg})$, where ' $\mathrm{LV}$ ' refers to a lone vacant orbital located on $\mathrm{Mg}^{2+}$. Fig. S5 (ESI $\dagger$ ) summarises the calculated coordination structures and their reduction potentials for the two-electron reduction process for the systems with and without the $\mathrm{BH}_{4}{ }^{-}$anion. The calculation shows that the reduction potential of $\mathrm{Mg}^{2+} / \mathrm{Mg}$ is the most negative $\left(-3.67 \mathrm{~V} v s . \mathrm{Ag}^{+} / \mathrm{Ag}\right)$ when $\mathrm{Mg}\left[\mathrm{NTf}_{2}\right]_{2}$ is considered in the absence of any other solvent ions. Upon introducing an IL1 ion pair to the calculation, the immediate co-ordination environment of the $\mathrm{Mg}$ ion remains the same and the potential shifts slightly to $-3.32 \mathrm{~V}$. The reduction potential shifts further positive to $-3.11 \mathrm{~V} v s$. $\mathrm{Ag}^{+} / \mathrm{Ag}$ when the $\left[\mathrm{BH}_{4}\right]^{-}$anion is introduced.

These potentials can be compared very approximately (allowing for the lack of a realistic solvent environment in both cases) with calculations of the IL anion reduction pathway and the corresponding potentials as shown in Fig. $3 \mathrm{~b}$. These show that the anions are themselves reduced in a similar potential range, producing cleavage of the anion and possibly insoluble reaction products. Indeed, Forsyth and co-workers have proved in their work that the anion in $\left[\mathrm{NTf}_{2}\right]$ based ILs easily reacts with magnesium metal, forming a protective film on the surface of the electrode. ${ }^{13}$ This suggests that the reduction potential is beyond the stability limit of the anion in the case of the $\mathrm{Mg}\left[\mathrm{NTf}_{2}\right]_{2} / \mathbf{I L 1}$ system but that the presence of the more weakly coordinating $\left[\mathrm{BH}_{4}\right]^{-}$ions raise the potential sufficiently to allow $\mathrm{Mg}$ reduction to become the predominant process.

On the other hand, Fig. S2b (ESI $\dagger$ ) illustrates the SEM, EDX and XRD results upon deposition from the $0.2 \mathrm{M} \mathrm{Mg}\left[\mathrm{BH}_{4}\right]_{2} / \mathbf{I L 2}$ system. Sulfur (S), oxygen (O), carbon (C) and fluorine (F) are all observed in the EDX. No Mg XRD peaks are observed, instead some small peaks consistent with $\mathrm{MgF}_{2}$ appear. ${ }^{14}$ The cleavage of the anion in this case produces $\mathrm{F}^{-}$(Fig. $3 \mathrm{~b}$ ) and it suggests that this process produces a passivating layer on the $\mathrm{Mg}$.

In summary, reversible magnesium deposition and stripping from an alkoxy-ammonium based RTIL has been demonstrated in this work. Both the experimental and theoretical data obtained here show the significance of the magnesium salt, specifically $\mathrm{Mg}\left[\mathrm{BH}_{4}\right]_{2}$ in achieving reversible $\mathrm{Mg}$ redox behaviour in IL1. DFT calculations indicate that the presence of weakly coordinating species such as $\left[\mathrm{BH}_{4}\right]^{-}$anions in the coordination environment of the $\mathrm{Mg}^{+}$state is important for the re-oxidization of $\mathrm{Mg}^{2+}$ ions. Both FT-IR and theoretical studies highlight the role of the weak $\mathrm{H}\left(\delta^{-}\right) \cdots \mathrm{Mg}^{2+}$ interactions taking place in IL1, as observed in the shift of the $\mathrm{BH}_{2}$ scissoring and rocking modes at approximately 1456 and $617 \mathrm{~cm}^{-1}$, respectively. Thus this paper highlights RTILs as potential candidates as electrolytes for rechargeable magnesium batteries.

\section{Notes and references}

$\mp$ Experimental section: the synthesis and characterisation of $\mathrm{N}$-ethyl-2(2-methoxyethoxy)- $N, N$-bis(2-(2-methoxyethoxy)ethyl)-ethan-1-aminium bis(trifluoromethylsulfonyl)imide (IL1) and $N$-ethyl-2-(2-methoxyethoxy)$N, N$-bis(2-(2-methoxyethoxy)ethyl)-ethan-1-aminium bis(fluorome-thylsulfonyl)imide (IL2), the $\left[\mathrm{N}_{2}(20201)(20201)(20201)\right]\left[\mathrm{NTf}_{2}\right]$ and $\left[\mathrm{N}_{2}(20201)(20201)\right.$ $(20201)][\mathrm{FSI}]$, in each case, is described in the ESI. $\dagger$ Magnesium borohydride 
$\left(\mathrm{Mg}\left[\mathrm{BH}_{4}\right]_{2}, 95 \%\right)$ and lithium borohydride $\left(\mathrm{LiBH}_{4}, 90 \%\right)$ were purchased from Sigma-Aldrich. The RTILs and salts were further dried under vacuum $\left(38{ }^{\circ} \mathrm{C}, 48 \mathrm{~h}\right)$ and all samples were prepared under inert conditions prior to conducting any experiments. All electrochemical experiments were conducted in a three-electrode cell using magnesium ribbon and platinum as the counter and working electrodes, in each case. Both $10 \mathrm{mM}$ silver triflate (AgOTf) dissolved in the RTIL and magnesium ribbon were used as reference electrodes. Full preparative and experimental details are provided in the ESI. $\dagger$

1 (a) L. W. Gaddum and H. E. French, J. Am. Chem. Soc., 1927, 49, 1295; (b) D. Aurbach, M. Moshkovich, A. Schechter and R. Turgeman, Electrochem. Solid-State Lett., 2000, 3, 31.

2 R. Mohtadi and F. Mizuno, Beilstein J. Nanotechnol., 2014, 5, 1291.

3 (a) F. Endres, ChemPhysChem, 2002, 3, 144; (b) D. R. MacFarlane and K. R. Seddon, Aust. J. Chem., 2007, 60, 3.

4 L. Lodovico, V. L. Martins, T. M. Benedetti and R. M. Torresi, J. Braz. Chem. Soc., 2014, 25, 460.

5 O. Shimamura, N. Yoshimoto, M. Matsumoto, M. Egashia and M. Morita, J. Power Sources, 2011, 196, 1586.

6 G. Vardar, A. E. S. Sleightholme, J. Naruse, H. Hiramatsu, D. Siegel and C. Monroe, ACS Appl. Mater. Interfaces, 2014, 6, 18033.
7 (a) T. Kakibe, J.-y. Hishii, N. Yoshimoto, M. Egashira and M. Morita, J. Power Sources, 2012, 203, 195; (b) N. Yoshimoto, K. Hotta, M. Egashira and M. Morita, Electrochemistry, 2012, 80, 774; (c) R. E. Doe, G. H. Lane, R. E. Jilek and J. Hwang, Google Pat., US 20130252112 A1, 2013; (d) P. Saha, M. K. Datta, O. I. Velikokhatnyi, A. Manivannan, D. Alman and P. N. Kumta, Prog. Mater. Sci., 2014, 66, 1.

8 (a) Y. NuLi, J. Yang and R. Wu, Electrochem. Commun., 2005, 7, 1105; (b) P. Wang, Y. NuLi, J. Yang and Z. Feng, Surf. Coat. Technol., 2006, 201, 3783; (c) Y. NuLi, J. Yang and P. Wang, Appl. Surf. Sci., 2006, 252, 8086.

9 R. Mohtadi, M. Matsui, T. S. Arthur and S.-J. Hwang, Angew. Chem., Int. Ed., 2012, 51, 9780.

10 While this paper was under review, the following article appeared reporting similar and concordant results: T. Watkins, A. Kumar and D. A. Buttry, J. Am. Chem. Soc., 2016, 138, 641.

11 K.-J. Jeon, H. R. Moon, A. M. Ruminski, B. Jiang, C. Kisielowski, R. Bardhan and J. J. Urban, Nat. Mater., 2011, 10, 286.

12 R. Černý, Y. Filinchuk, H. Hagemann and K. Yvon, Angew. Chem., Int. Ed., 2007, 46, 5765.

13 M. Forsyth, P. C. Howlett, S. K. Tan, D. R. MacFarlane and N. Birbilis, Electrochem. Solid-State Lett., 2006, 9, B52.

14 T. Pilvi, T. Hatanpaa, E. Puukilainen, K. Arstila, M. Bischoff, U. Kaiser, N. Kaiser, M. Leskela and M. Ritala, J. Mater. Chem., 2007, 17, 5077. 